\title{
AGE AND SEX FACTORS IN CORONARY ARTERY DISEASE
}

\author{
BY \\ A. A. FITZGERALD PEEL \\ From the Cardiac Department, Victoria Infirmary, Glasgow \\ Received January 12, 1955
}

Age and sex have hitherto received less consideration than they merit in publications dealing with prognosis and mortality in coronary artery disease. Yet a clear knowledge of all factors that influence mortality is of paramount importance at a time when the efficicacy of modern methods of treatment is under critical review. Even in the matter of their influence on ætiology, age and sex have received less prominence than the facts would seem to justify.

It is common knowledge that coronary artery disease is much more frequent in men than women: estimates have varied between seven to one (Mackenzie, 1923) and four to one (Block et al., 1952). It is also widely recognized that coronary artery disease reaches its maximum incidence in the fifth, sixth, and seventh decades of life. Nevertheless few references can be found to the striking difference between the age incidence in males and that in females. Block et al. (1952) hint at the existence of such a difference when they state that the preponderance of men becomes less in the older age groups. Johnston (1954) thinks the age incidence is about ten years later in women than in men.

Mortality figures are usually quoted for entire groups of patients comprising both sexes and all ages, as though the mortality were not appreciably affected by age or sex. Yet, without actually saying so, Mackenzie (1923) implies that the disease is more rapidly fatal in the elderly than in the young when he writes (p. 138) "If we put aside the relatively few patients in whom death occurred before 50 years of age we will find that the deaths follow closely that of the general death rate " (my italics). Of his 214 patients whose age at death is given (p. 118), 24 were aged under 50; the largest number of deaths occurred in the quinquennium 61-65 (p. 116). The figures of Block et al. (1952) show a steadily diminishing percentage of survivors, both at five and at ten years after onset, as the age at onset advances from under 40 to over 80. Cole et al. (1954) quote figures that show a later incidence in women than men, a steadily rising mortality in men as age increases, a relatively higher mortality in women than in men of the lower age groups, and a considerably smaller rise in mortality with increasing age in women.

\section{Material AND Methods}

The investigations, in the course of which the present observations were made, were originally begun for a different purpose, namely to assess the immediate and remote prognosis in patients who have had what may be termed an " acute coronary episode." The material therefore includes patients who have experienced such an episode-an attack of cardiac infarction, an attack of angina pectoris (" acute coronary insufficiency" or " acute cardiac ischæmia "), abrupt onset of effort angina, or abrupt change in the severity or behaviour of pre-existing effort angina. It does not include cases of chronic angina of effort which have started so insidiously and progressed so slowly that no definite " episode" could be recognized. The patients were seen in consulting practice from 1930 up till the end of 1953, and the material therefore covers a wider range of severity than series based on hospital admissions. Analogous cases referred to the outpatient department or admitted to the cardiac wards of the Victoria Infirmary, Glasgow, between January, 1951, and December, 1953, have also been studied. 
For purposes of age and sex incidence, the entire group has been used. For purposes of mortality and survival records, only the 1930-50 consulting practice cases are used. These form a "pre-anticoagulant" series of cases, intended as a yardstick for comparison in due course with corresponding figures from 1951 onwards, this being the time when treatment of selected cases by anticoagulants was begun on a large scale. Prior to 1950 , only four patients in the entire series received anticoagulant treatment. Twelve patients treated with anticoagulants in 1950 have been excluded from the series.

A diagnosis of cardiac infarction has been based on either $(a)$ characteristic changes in the QRS complex of the cardiogram; $(b)$ changes confined to RT and T if accompanied by pericardial friction, fever, or leucocytosis, or if followed by embolism; $(c)$ in the absence of a cardiogram, a typical clinical picture if followed by embolism or confirmed by necropsy. A diagnosis of cardiac ischamia has been made when cardiographic changes have been confined to RT or T and have not been followed by one or other of the signs mentioned in $(b)$ above. Cardiac ischæmia has also been accepted as a diagnosis when typical coronary pain has occurred either at rest or on effort, even though the cardiogram has been normal after the pain has subsided.

The immediate mortality and short-term prognosis (up to six weeks) have been assessed in relation to "attacks"; that is to say, a patient who takes a second attack a few months or years after apparent recovery from the first one, is included for this purpose on both occasions. Longterm survival has been assessed in relation to single patients irrespective of the number of attacks each may have experienced: each patient is included once only, and the survival period is given from the date of the first attack.

Survivors are included in the tables for the number of years they are known to have survived; likewise, deaths are included only for the number of years they have been dead. Thus the figures for deaths and survivors at five years includes all patients seen up to and including 1949 while the ten-year figure includes those seen up to the end of 1944. They are based on the information available up to December 31, 1954.

\section{Discussion}

Age and Sex Incidence. The overall proportion of males to females was four to one. However this ratio varies in different age groups. The youngest male was aged 28 , and there were several between this age and 43 which was the age of the youngest female. Below age 50 the ratio of males to females was seven to one; between 50 and 59 it was almost ten to one. From 60 to 69 the ratio had dropped to just over four to one, while from 70 onwards it was under two to one.

In males the incidence remains very low up to the age of 40 when it begins to rise steeply, reaching a high peak in the age group 55-59; thereafter it falls almost as steeply as it rose (Fig. 1). In females on the other hand, the rise in incidence is slow but steady, almost in a straight line from age 40 to 70 . It seemed possible that these findings might be due to the composition of the population at risk, females outnumbering males in the higher age groups. Population statistics were therefore obtained from the Registrar-General for Scotland, and in Fig. 2 the number of cases in each age-sex group has been adjusted upwards or downwards to make it " per 100,000 persons living " of that sex and in that age group. Far from abolishing the sex differences, this has only served to emphasize them. The female incidence approaches even more closely to a straight line. The low incidence in males under 40 becomes more striking, the ascending limb of the incidence curve is smoothed out, the peak at age 55-59 persists, and the striking fall after that age remains.

It is clear that these differences in incidence must imply different ætiological factors affecting the two sexes. The female incidence is what might be expected in a disease associated with the processes of ageing. In this case some additional factor must be present in males aged 40-59 to produce the rapidly rising incidence, and must cease to operate at or about age 60 to account for the diminishing incidence above that age. It might be tempting to blame occupational factors if the peak occurred at age 65; but if occupation were responsible it is difficult to see why the incidence should be falling steeply during the five years before the common retiring age, at the very time when the effects of lifelong occupation might be expected to be exerting their maximal influence. An alternative hypothesis was put forward by Oliver (1954) in a dis- 
cussion at the Glasgow meeting of the British Medical Association; he suggested that in females an inhibitory factor may te present during the sexually active period of life. This could account for the extremely low incidence in younger women, and for the later rise in that sex; but it could not explain the steep fall in males after the age of 60 , a fall that occurs while the female incidence is still rising.

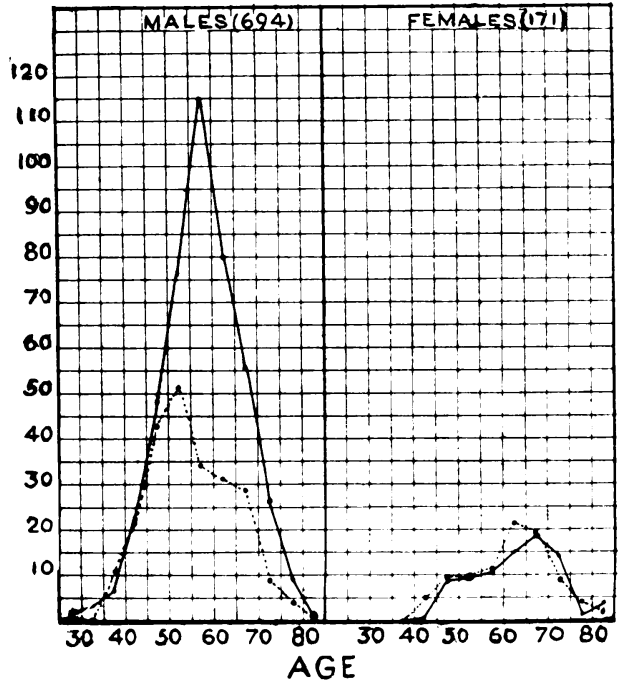

FIG. 1.-Age and sex incidence of coronary attacks. Cardiac infarction •-•. Ischæmia without infarction. $\cdots \cdots=$.

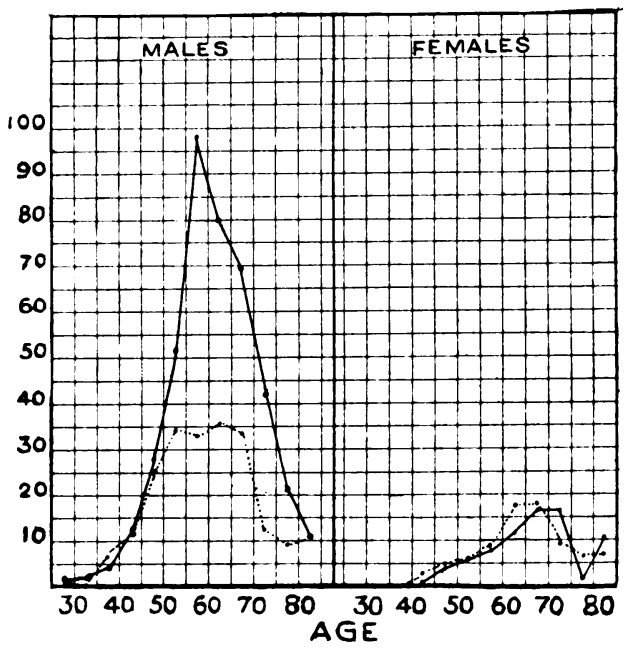

FIG. 2.-Age and sex incidence of coronary attacks, adiusted to correspond to 100,000 living in each quinquennium. Cardiac infarction - - •. Ischæmia without infarction. $0 \cdots \cdots$.

Cardiac Infarction and Cardiac Ischamia. A second interesting difference between the sexes, also shown in Fig. 1 and 2, is in the ratio between attacks with (continuous line) and without (dotted line) infarction. In females attacks with and without infarction are almost equal in number at all ages; the continuous and dotted lines follow one another closely. Thus half the "coronary episodes " in women are associated with infarction while no infarction occurs in the remaining half. In males the same state of affairs is found up to age 50 ; but once this age is passed infarction becomes much more frequent. Three-quarters of the "coronary episodes " in males over 50 result in infarction.

It is becoming increasingly recognized that "coronary occlusion" and "cardiac infarction" are not interchangeable terms. Snow et al. (1952) mention three hearts in which a single occlusion gave rise to two anatomically separate infarcts. Conversely, Blumgart et al. (1940) found 53 main vessel occlusions with only 16 infarcts in a series of 30 hearts; while Ravin and Geever (1946) examined at necropsy 166 unselected hearts of which 13 showed occlusion without infarction. Papp and Shirley Smith (1951) postulate coronary occlusion resulting in multiple small areas of necrosis as one possible basis for what they call "slight coronary attacks": signs of gross infarction are absent; the end result may be small intramural scars, and the cardiogram returns to normal. These variations in the effects of coronary occlusion are clearly related to the size of the occluded vessel, the rate at which occlusion develops, and the capacity to provide a collateral circulation. Blumgart et al. (1950) found inter-arterial communications in 15 per cent of healthy hearts. Laubry and Soulié (1950) found these in 4 out of 5 healthy hearts from patients under 30,16 out of 49 at ages between 40 and 70 , and 4 out of 14 at ages over 70 ; in healthy hearts they were small but in hearts with coronary disease they were much larger.

If we assume that " coronary episodes" are associated with partial or complete occlusion of a larger or smaller coronary vessel, and that the subsequent development of infarction depends on inability to produce an adequate collateral circulation, we can explain the differences between males and females on the assumption that both sexes start life with a capacity to provide a collateral circulation which is sufficiently well developed to prevent infarction in approximately half the instances of coronary occlusion: 
females apparently retain this capacity throughout life, but males seem to lose it to a large extent once the age of 50 has been passed.

Mortality. When the differences in ætiology and behaviour of coronary artery disease in the two sexes are considered it would indeed be surprising if the mortality rates were uniform. Table I gives the mortality during the first six weeks after a cardiac infarct for males and females at different age periods, in our " preanticoagulant" series. In males, the mortality is quite low below the age of 50 (under $5 \%$ ); there is a steady rise thereafter until the age of 65 when the figure reaches 35 per cent. The total number of females in the series is too small to allow comparison between different age groups; but the figures, such as they are, suggest that in females the mortality is much more uniformly spread over the different age groups, and that the rise in mortality with increasing age is indeed small (Table I).

The rising mortality with increasing age in males, and the more level mortality at all ages in females, accords well with the suggestions already made regarding the capacity to produce a collateral circulation in the two sexes. On the other hand the total mortality in females at all ages from cardiac infarction is

TABLE I

Mortality in the First Six Weeks after Cardiac Infarction. Influence of Age and Sex (1930-50 “ Pre-anticoagulant" Series)

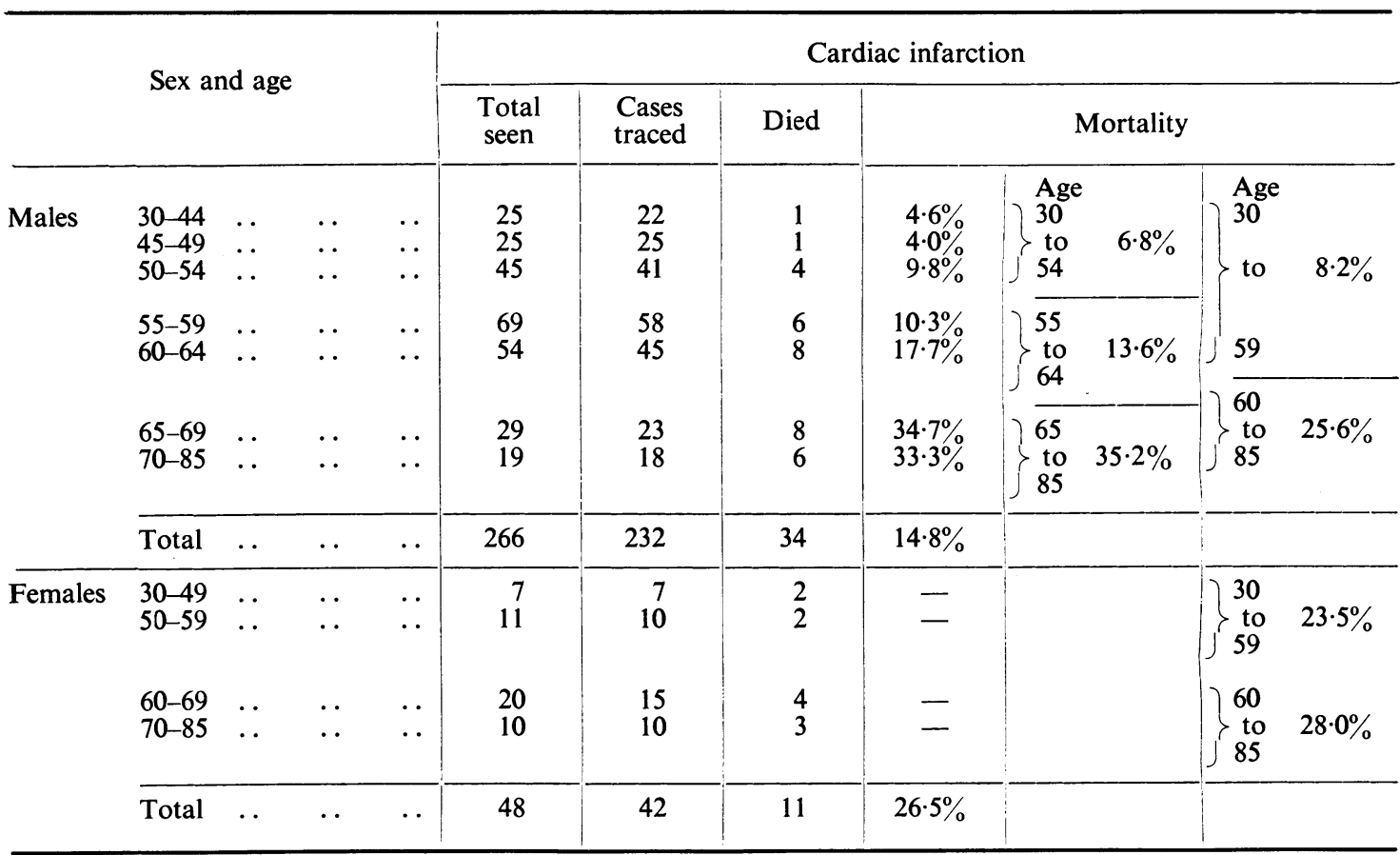

Note-Only 4 cases in this series received anticoagulants. A male, aged 47, died 6th day; a male, aged 59, survived one year; a male, aged 62, survived just over two years; a male, aged 63, alive when last heard of two years later. Exclusion of these 4 cases from the series would emphasize the difference in male mortality between the younger and older age groups.

almost double that in males. This finding is entirely unexpected, not only in view of the conclusions already reached regarding the capacity to provide a collateral circulation in the two sexes, but also having regard to the fact that females generally have a better life expectation than males of the same age. The severity of individual attacks will not explain the greater mortality in females in this series. The ratio of " severe " to " mild" attacks in males (117 to 111) and in females (23 to 21) was almost identical. (In 6 males the available information is inadequate to determine whether the attack was "severe" or " mild"; in two females the severity is known but the age has not been recorded.) Attacks were classified as " severe" if accompanied either by signs of shock or by symptoms of heart failure whether left-sided or right-sided. These two factors are of extreme prognostic importance, irrespective of age and sex, as shown by Table II. 
TABLE II

Influence of Shock and Heart Failure Upon Mortality in Cardiac Infarction

\begin{tabular}{|c|c|c|c|c|c|c|c|c|c|}
\hline \multirow{2}{*}{\multicolumn{4}{|c|}{$\begin{array}{l}\text { Cardiac } \\
\text { infarction }\end{array}$}} & \multicolumn{3}{|c|}{ Present } & \multicolumn{3}{|c|}{ Absent } \\
\hline & & & & Cases & Died & Mortality & Cases & Died & Mortality \\
\hline Shock .. & . & $\ldots$ & $\ldots$ & 112 & 36 & $32 \cdot 1 \%$ & 166 & 8 & $4.8 \%$ \\
\hline Failure & $\ldots$ & $\ldots$ & $\ldots$ & 73 & 23 & $31.8 \%$ & 205 & 21 & $10 \cdot 3 \%$ \\
\hline
\end{tabular}

Cardiac Ischamia. During the corresponding period (1930-50) 167 cases were seen and diagnosed as cardiac ischæmia according to the criteria already enumerated; of these, 150 were followed for at least 6 weeks, some for as long as 15 years. In 17 cases $(16$ males) symptoms of infarction developed within 6 weeks of the onset; one of them died on the first day of his infarction, a male, aged 62 ; the remaining 16 survived the attack. These cases are already included in the tables as cases of cardiac infarction. In 133 cases of cardiac ischæmia no infarct followed during the first six weeks and the mortality in these cases was quite low. Of 93 males, two died within six weeks, one in the 50-54 and one in the 55-59 age group; of 40 females, two died, one in the 55-59 and one in the 60-64 age group. Thus the immediate mortality was $2 \cdot 2$ per cent for males, 5 per cent for females, and 3 per cent for both sexes combined in the cases of simple ischæmia. If the cases that started as ischæmia and subsequently developed infarct are included, the mortality was 2 per cent in males and 4.9 per cent in females.

However, the incidence of infarction in cases that start as ischæmia may in fact be higher than the foregoing figures would suggest. During the same period 117 patients who already had cardiac infarction when first seen gave a history of prodromal symptoms; some of them would no doubt have shown signs of infarction even in the prodromal period, but a number would have been diagnosed as ischæmia in this stage. It is suggested therefore that the incidence of infarction within six weeks of the onset of ischæmia is not greater than one in three and not less than one in ten. These figures are of importance in assessing the prophylactic use of anticoagulants to prevent infarction in cases of ischæmia.

It is of passing interest to note that the mortality was a little lower in cases of cardiac infarction with a history of prodromal symptoms $(13 \%)$ than in those with abrupt onset and no warning $(17 \%)$. A history of previous cardiovascular disease-hypertension, cerebral vascular lesions, angina of effort, or previous coronary episodes-increased the mortality of cardiac infarction from 13 per cent to 17.5 per cent.

The Long-Term Prognosis after Coronary Episodes. The first four weeks cover the most dangerous period after cardiac infarction; 40 out of 45 deaths occurred within the first 28 days and the majority of these took place in the first fortnight. The long-term prognosis becomes a problem once a patient has successfully weathered the first four dangerous weeks. The observations that follow are based on the fate of 240 patients who were still alive four weeks after the onset of their attack. Table III gives for each age group (i) the original number of survivors; (ii) the position at the end of the 1st, 3rd, 5th and 10th years; (iii) the latest year at the end of which half or more than half the patients traced were still alive; and (iv) the longest survival period so far reached.

Although the number of females is small, it would appear that the age at onset is the most important factor in determining the probable expectation of life; this was longest in the youngest age groups and diminished steadily with advancing age. Since there were relatively more women in the older age groups, women as a whole compared unfavourably with men; but when the age at onset is taken into consideration, the younger women (under 50) tended to outlive the men. In males, the optimum age from the point of view of life expectancy was from 50 to 54; these patients survived on the average for 6 years whereas those of 45 to 49 averaged only 5 years, and those under 45 only 4 years. A possible explanation may lie in the change of temperament that is apt to occur about the age of 50. The restriction of activity necessary after recovery from a cardiac infarct tends to be more trying and irritating to the younger man and may perhaps be less strictly observed by him. After the age of 55 the expectation of life diminishes rapidly although individual patients may survive for long periods. The worst expectation was at age 60 to 64 ; half the patients in this group died before completing their third year. Those between 65 and 74 fared somewhat better, but three of the four original survivors who were aged 75 or over had died within three months. It may here be remarked that Smith (1942 and 1953) followed up 100 consecutive cases for 20 years but observed no relationship between age and survival period. 
TABLE III

Follow-up of Patients Surviving Cardiac Infarction and Cardiac Ischemia more than Four Weeks

\begin{tabular}{|c|c|c|c|c|c|c|c|c|c|c|}
\hline \multirow[t]{2}{*}{ - } & \multirow{2}{*}{$\begin{array}{c}\text { Alive } \\
\text { after } \\
4 \text { weeks }\end{array}$} & \multicolumn{4}{|c|}{$\begin{array}{c}\text { Number traced and number alive } \\
\text { at end of year }\end{array}$} & \multicolumn{3}{|c|}{$\begin{array}{c}\text { Half still alive at end of } \\
\text { year }\end{array}$} & \multicolumn{2}{|c|}{$\begin{array}{l}\text { Longest } \\
\text { survival }\end{array}$} \\
\hline & & 1 & 3 & 5 & 10 & Year & Traced & Alive & Years & No \\
\hline $\begin{array}{l}\text { Infarcts } \\
\text { Males } \\
30-44 \\
45-49 \\
50-54 \\
55-59 \\
60-64 \\
\\
65-69 \\
70-74 \\
75-85\end{array}$ & $\begin{array}{r}23 \\
23 \\
36 \\
56 \\
37 \\
\\
16 \\
9 \\
4\end{array}$ & $\begin{array}{r}17-12 \\
18-17 \\
26-23 \\
42-33 \\
27-24 \\
\\
15-11 \\
7-5 \\
3-1\end{array}$ & $\begin{array}{r}16-9 \\
18-15 \\
22-13 \\
40-23 \\
19-8 \\
14-7 \\
6-4 \\
3-0\end{array}$ & $\begin{array}{r}9-2 \\
14-8 \\
19-11 \\
32-12 \\
15-4 \\
12-4 \\
4-1 \\
3-0\end{array}$ & $\begin{array}{r}3-0 \\
3-0 \\
11-2 \\
11-1 \\
8-1 \\
3-2 \\
2-0 \\
0\end{array}$ & $\begin{array}{l}4 \\
5 \\
6 \\
4 \\
2 \\
3 \\
4 \\
\text { u }\end{array}$ & $\begin{array}{c}14 \\
14 \\
19 \\
37 \\
23 \\
\\
14 \\
4 \\
\text { der } 3 \text { mor }\end{array}$ & $\begin{array}{r}7 \\
8 \\
10 \\
18 \\
16 \\
\\
7 \\
3\end{array}$ & $\begin{array}{l}7 \\
9 \\
14 \\
14 \\
14 \\
\text { (died } \\
20 \\
5 \\
1\end{array}$ & $\begin{array}{c}2 \\
1 \\
2 \\
1 \\
1 \\
5 \text { th) } \\
1 \\
1 \\
1\end{array}$ \\
\hline $\begin{array}{c}\text { Females } \\
30-44 \\
45-49 \\
50-54 \\
55-59 \\
60-64 \\
65-69 \\
70-74 \\
75-85\end{array}$ & $\begin{array}{l}1 \\
5 \\
4 \\
5 \\
7 \\
7 \\
6 \\
1\end{array}$ & $\begin{array}{l}0 \\
3-2 \\
4-4 \\
4-2 \\
3-2 \\
5-4 \\
5-1 \\
1-0\end{array}$ & $\begin{array}{l}3-2 \\
3-2 \\
4-2 \\
2-0 \\
4-1 \\
5-1 \\
1-0\end{array}$ & $\begin{array}{ll}3- & 2 \\
2- & 1 \\
3-0 \\
2-0 \\
3- & 1 \\
4-0 & 0 \\
0 & \end{array}$ & $\begin{array}{l}2-1 \\
1-0 \\
1-0 \\
2-0 \\
1-0 \\
1-0\end{array}$ & $\begin{array}{r}10 \\
5 \\
4 \\
2 \\
2\end{array}$ & 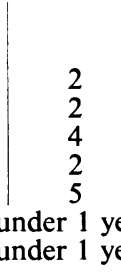 & $\begin{array}{l}1 \\
1 \\
2 \\
1 \\
4\end{array}$ & $\begin{array}{r}17 \\
5 \\
4 \\
2 \\
6 \\
3 \\
-\end{array}$ & $\begin{array}{l}1^{*} \\
1 \\
2 \\
1 \\
1 \\
1\end{array}$ \\
\hline $\begin{array}{c}\text { Ischæmia } \\
\text { Males } \\
30-44 \\
45-49 \\
50-54 \\
55-59 \\
60-64 \\
65-69 \\
70-74 \\
75-85\end{array}$ & $\begin{array}{r}15 \\
16 \\
19 \\
16 \\
16 \\
4 \\
4 \\
1\end{array}$ & $\begin{array}{r}12-11 \\
11-11 \\
11-11 \\
9-6 \\
8-7 \\
4-4 \\
4-4 \\
1-1\end{array}$ & $\begin{array}{r}10-9 \\
9-8 \\
10-10 \\
6-3 \\
6-5 \\
4-3 \\
4-4 \\
1-1\end{array}$ & $\begin{array}{l}9-7 \\
6-6 \\
6-4 \\
6-3 \\
4-3 \\
4-3 \\
3-2 \\
1-1\end{array}$ & $\begin{array}{l}5-2 \\
2-1 \\
2-1 \\
3-0 \\
0 \\
1-0 \\
2-0 \\
0\end{array}$ & $\begin{array}{r}9 \\
10 \\
10 \\
8 \\
5 \\
7 \\
5 \\
5\end{array}$ & $\begin{array}{l}6 \\
2 \\
2 \\
5 \\
4 \\
3 \\
3 \\
1\end{array}$ & $\begin{array}{l}3 \\
1 \\
1 \\
3 \\
3 \\
2 \\
2 \\
1\end{array}$ & $\begin{array}{r}12 \\
10 \\
15 \\
9 \\
5 \\
7 \\
5 \\
6\end{array}$ & $\begin{array}{l}1 \\
1 \\
1 \\
1 \\
3 \\
2 \\
2 \\
1\end{array}$ \\
\hline $\begin{array}{c}\text { Females } \\
30-44 \\
45-49 \\
50-54 \\
55-59 \\
60-64 \\
65-69 \\
70-74 \\
75-85\end{array}$ & $\begin{array}{r}3 \\
2 \\
3 \\
5 \\
14 \\
6 \\
1 \\
4\end{array}$ & $\begin{array}{l}2-1 \\
0 \\
2-2 \\
2-1 \\
10-9 \\
3-2 \\
0 \\
2-2\end{array}$ & $\begin{array}{l}1-0 \\
2-2 \\
2-1 \\
6-3 \\
3-2 \\
2-2\end{array}$ & $\begin{array}{l}1-0 \\
2-1 \\
1-1 \\
5-2 \\
2-1 \\
2-1\end{array}$ & $\begin{array}{l}1-0 \\
0 \\
0 \\
4-0 \\
1-0 \\
2-0\end{array}$ & $\begin{array}{l}2 \\
5 \\
7 \\
4 \\
6 \\
5\end{array}$ & $\begin{array}{l}2 \\
2 \\
1 \\
6 \\
2 \\
2\end{array}$ & $\begin{array}{l}1 \\
1 \\
1 \\
1 \\
3 \\
1 \\
1\end{array}$ & $\begin{array}{l}2 \\
\\
5 \\
7 \\
8 \\
6 \\
\\
5\end{array}$ & $\begin{array}{l}1 \\
1 \\
1 \\
1 \\
1 \\
1\end{array}$ \\
\hline
\end{tabular}

* This patient developed an aneurysm of the left ventricle within 6 months of her original attack in $1937 . \quad$ She is still alive. The walls of the aneurysm have been calcified for at least the last three years.

The expectation of life after an attack of cardiac ischæmia is approximately twice as long as that after cardiac infarction. This was found in both sexes and at all ages with the exception of one group (females, 30 to 44 ) in which the numbers are too few to justify any conclusion.

Apart from age and sex, the factors affecting length of survival are shock or failure at the time of the original attack, and the previous history. Of these failure is the most important; half of the survivors from attacks accompanied by failure died within two years. Half the patients who survived an attack with shock had died before the end of the third year; and half those who gave a history of previous cardiovascular disease likewise died within three years.

Mode of Death. Infcrmation regarding 81 deaths is available either from the patient's medical attendant or from personal observation; the causes of death are summarized in Table IV, which also gives the numbers dying at specified intervals after the attack. In 44 cases the date of death has been obtained from the patient's acquaintances or from newspaper notices and the mode of death is unknown. 
TABLE IV

Mode of Death and Period of Survival in 81 Cases of Cardiac Infarction

\begin{tabular}{|c|c|c|c|c|c|c|c|c|c|}
\hline \multicolumn{3}{|c|}{ Mode of death } & \multirow{3}{*}{$\begin{array}{c}\text { Number } \\
25\end{array}$} & \multicolumn{6}{|c|}{ Interval after original attack } \\
\hline Nived or deat & & & & $\begin{array}{c}\text { 4-13 } \\
\text { weeks }\end{array}$ & $\begin{array}{c}3-12 \\
\text { months }\end{array}$ & $\begin{array}{c}1-2 \\
\text { years }\end{array}$ & $\begin{array}{c}2-3 \\
\text { years }\end{array}$ & $\begin{array}{c}3-5 \\
\text { years }\end{array}$ & $\begin{array}{c}\text { Over } 5 \\
\text { years }\end{array}$ \\
\hline Subsequent attack & .. & . & & 4 & 2 & 4 & 4 & 6 & 5 \\
\hline Cardiac failure .. & . & . & 23 & 5 & 11 & 3 & 2 & 1 & $1^{*}$ \\
\hline Sudden death $\quad .$. & . & . & 16 & 1 & 4 & 2 & 5 & 2 & 2 \\
\hline Embolism $†$ & . & . & 5 & 3 & 1 & 1 & & & \\
\hline Cerebral thrombosis & . & .. & 4 & 0 & 0 & 1 & 0 & 1 & 2 \\
\hline Bronchial carcinoma & . & .. & 3 & 0 & 2 & 1 & & & \\
\hline Carcinoma elsewhere & . & .. & 2 & 0 & 0 & 0 & $\mathbf{0}$ & 0 & 2 \\
\hline Prostatic uræmia & .. & .. & 1 & 1 & & & & & \\
\hline Virus pneumonia & .. & .. & 1 & 1 & & & & & \\
\hline Intestinal obstruction & .. & .. & 1 & 0 & 0 & 0 & 0 & 1 & \\
\hline
\end{tabular}

* Failure in this case was precipitated by a prostatectomy 9 years after the original attack.

$\dagger$ Excluding emboli that occurred during the first four weeks (36) emboli that occurred during subsequent attacks (7) and emboli during or immediately before fatal failure (4). There were also 5 instances of embolism occurring after the fourth week which did not prove fatal.

Almost one-third of the deaths occurred in a second or subsequent attack, and these deaths are more or less evenly spread over the ensuing years being only a little more common in the first than in later years. Cardiac failure accounted for nearly another third, but most of the deaths from this cause occurred within the first year. One death in every five occurred quite suddenly while the patient was engaged in his usual daily routine; these deaths again were spread over the years, being perhaps a little more common in the first and third than in other years. In view of the widespread apprehension regarding sudden death after cardiac infarction or ischæmia it is interesting to note that 180 patients were traced to the end of the first year after a cardiac infarct and four of them had died suddenly during the year. The corresponding figures after attacks of cardiac ischæmia are 81 traced of whom one died suddenly.

The occurrence of three deaths from bronchial carcinoma soon after a coronary thrombosis seems worthy of comment. I have knowledge also of a fourth case, not included in the series as he was never examined by me but was a friend of the family; he suffered from angina of effort for about two years before his death from bronchial carcinoma. A fifth patient was seen in 1954 with angina of effort and cardiographic signs of infarction; he is now suffering from a bronchial carcinoma. Finally, a sixth patient was referred to the outpatient department some years ago with a typical history of coronary thrombosis seven weeks previously, cardiographic signs of transmural anterior infarction, hæmoptysis, physical signs in the left lower lobe, and an X-ray shadow that was at first thought to be an infarct; serial X-ray examinations over the next few weeks demonstrated that the lesion was a bronchial carcinoma. This incidence of bronchial carcinoma after cardiac infarction seems much too high to be purely accidental. It will be noted, moreover, that the deaths from bronchial carcinoma occurred within two years, whereas the two deaths from carcinoma elsewhere took place more than five years later. It seems likely that in these cases the original coronary thrombosis was an early symptom of the developing bronchial carcinoma, analogous to the superficial or deep venous thrombosis that sometimes heralds the onset of this disease.

\section{SUMMARY}

The age incidence of coronary attacks has been compared in men and women in a series of 865 cases. In men the incidence starts earlier, reaches a high peak at age 55 to 59 , and thereafter falls steeply. 
In women the rise in incidence is slow and steady from age 40 to age 70 ; there is no ultimate fall in incidence comparable to that seen in men. One-half the "coronary episodes" in women result in infarction; one-half the coronary episodes in men under 50 result in infarction, but after the age of 50 three-quarters produce infarcts. The ætiological and pathological implications of these differences are discussed.

The immediate mortality in 276 cases of cardiac infarction which were treated before anticoagulants were adopted has been analysed in relation to age and sex. In men the mortality rises steadily from 5 per cent at ages under 44 to 35 per cent at ages over 65 ; in women the mortality is approximately 25 per cent in all age groups, rising only slightly as age advances.

The long-term prognosis has been studied in 240 survivors from cardiac infarction and 129 survivors from attacks of cardiac ischæmia. The best expectation of life was found in men aged 50 to 54 who fared better than younger men; the worst expectation was at age 60 to 64 . In women the expectation was best at ages below 50 and diminished progressively as the age at onset increased. The ultimate cause of death and the time at which they are most likely to occur are also discussed.

The mortality and survival figures are intended as a basis of comparison with figures to be published dealing with a later series in which anticoagulants have been used for selected cases.

It is a pleasure to acknowledge the help of numerous general practitioners who have provided information regarding the subsequent history of patients with coronary disease referred by them: without their aid, this follow-up would have been impossible. I would also express my appreciation of the help given by my secretary Miss A. Watson, and by Mrs. E. Yarr at the Victoria Infirmary.

\section{REFERENCES}

Block, W. J., Crumpacker, E. L., Dry, T. J., and Gage, R. P. (1952). J. Amer. med. Assoc., 150, 259.

Blumgart, H. L., Schlesinger, M. J., and Davis, D. (1940). Amer. Heart J., 1, 19. , Zoll, P. M., Freedberg, A. S., and Gilligan, D. R. (1950). Circulation, 1, 11.

Cole, D. R., Singian, E. B., and Katz, L. N. (1954). Circulation, 9, 321.

Johnston, J. M. Personal communication.

Laubry, C., and Soulié, P. (1950). Les Maladies des Coronaires. Paris.

Mackenzie, J. (1923). Angina Pectoris. Oxford Med. Publications, London.

Oliver, M. F. (1954). Discussion on coronary artery disease, British Medical Association Annual Meeting, Glasgow.

Papp, C., and Smith, K. S. (1951). British Heart J., 13, p. 17.

Ravin, A., and Geever, E. F. (1946). Arch. intern. Med., 78, 125.

Smith, C. (1942). Ann. intern. Med., 17, 681. (1953). J. Amer. med. Assoc., 151, 167.

Snow, P. J. D., Morgan Jones, A., and Daber, K. (1952). Proceedings British Cardiac Society, Brit. Heart J., $14,542$. 